\title{
Analysis of Vibration of Roadheader Rotary Table Based on Finite Element Method and Data from Underground Coalmine
}

\author{
Minjun Zhang $\mathbb{D}^{1},{ }^{1}$ Fuyan Lyu, ${ }^{2}$ Xiushan Tang, ${ }^{1}$ Yang Yang, ${ }^{3}$ Xiaodong $\mathrm{Ji}^{3}$ and Miao Wu ${ }^{1}$ \\ ${ }^{1}$ School of Mechanical Electronic \& Information Engineering, China University of Mining and Technology, Beijing 100083, China \\ ${ }^{2}$ College of Mechanical and Electronic Engineering, Shandong University of Science and Technology, Qingdao, Shandong 266590, China \\ ${ }^{3}$ Shijiazhuang Coal Mining Machinery Co. Ltd., Shijiazhuang, Hebei 050000, China \\ Correspondence should be addressed to Minjun Zhang; zmj0424@qq.com
}

Received 5 August 2017; Accepted 12 February 2018; Published 19 March 2018

Academic Editor: Longjun Dong

Copyright ( 2018 Minjun Zhang et al. This is an open access article distributed under the Creative Commons Attribution License, which permits unrestricted use, distribution, and reproduction in any medium, provided the original work is properly cited.

\begin{abstract}
The intense vibration of a roadheader rotary table damages the cutting system of the roadheader and reduces the efficiency. This paper analyzes the vibration of a rotary table by combining the finite element model with tested data from an underground coalmine. First, the force of the rotary table during the cutting procedure was analyzed, and the finite element model was built using Pro/E and ADAMS. The tested data were then imported into the model after selection, procession, and combination were conducted. Next, the six lowest-order parameters of the rotary table were calculated. A vibration analysis of the rotary table under certain working conditions was conducted, and the results were compared with those from a modal experiment using a single-point excitation method. According to the comparison between the simulation result and experiments, it is clear that this method is both reasonable and feasible. And it could supplement the theoretical foundation of the analysis of other roadheader components, providing reference for the improvement of the structure and dynamic properties of a roadheader. In addition, other vibration components of a roadheader such as the cutting head and the cutting arm could also be analyzed through the proposed method, with very reliable precision.
\end{abstract}

\section{Introduction}

A roadheader is the most important piece of equipment in the deep mining industry for excavating a roadway. Its reliability and efficiency are crucial to the production efficiency of the deep mining. The breakdown of the roadheader would lead to the interruption of the roadway tunneling. According to statistics, most problems in a roadheader are caused by vibration, particularly in the cohesive components. During the cutting process, severe irregular vibration can be caused by a nonuniform work medium, varying degrees of hardness, and irregular shape of the rock [1-4]. These vibrations have a direct effect on the cutting arm, and the rotary table is the bridge between the cutting arm and body. Therefore, the rotary table plays an important role in the roadheader. The rotary table is usually impacted by a complex and variable load, which could lead to the fatigue cracking [5]. Therefore, the present research focuses on an analysis of roadheader vibration with an aim to control any harm occurring from such vibration. Moreover, via the analysis of the vibration of the rotary table, vulnerable spots could be located which could be helpful to the improvement of reliability and stability of the roadheader [6].

There are a lot of vibration analysis methods, such as the bond graph theory method, but the working condition of the deep mining is very special compared with other fields [7]. Aiming for a more accurate analysis, some researches have discussed the vibration different components of a roadheader working in the deep mining. A virtual prototype [8] was employed for simulating a vibration model of roadheader cutting head, and the load of the cutting head was calculated based on a theoretical method imported into the finite element model. An analysis of the dynamics of the cutting arm and a simplified 3D model using SolidWorks was also 


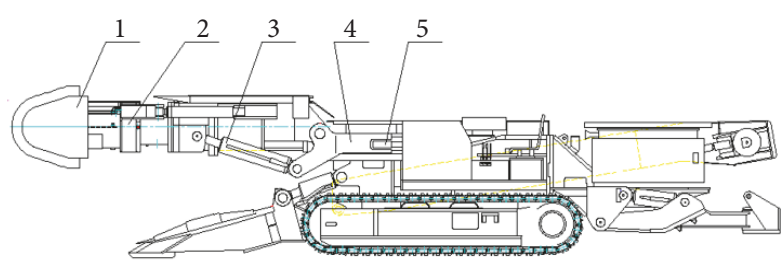

(a) The location of the rotary table on the roadheader

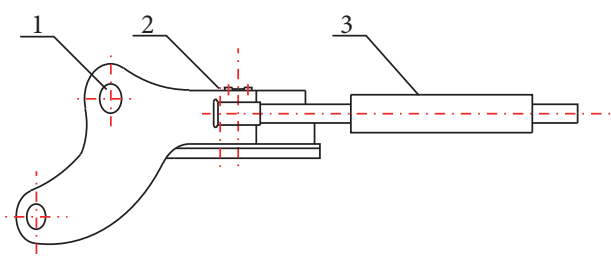

(b) The general rotary table structure

FIGURE 1: Location of the rotary table on a roadheader and the general rotary table structure.

described [9], where ADAMS was used for a simulation of the simplified model. A force analysis and kinetic equations of the roadheader under deep mining working conditions were proposed [10], and, to simplify the calculation, some insignificant variables and coefficients were ignored. A roadheader EBZ135 working in deep mining was also modeled using virtual prototype technology [11], and the force and vibration of its rotary table were simulated using ADAMS.

Modal analysis theory has increasingly been matured in recent years, and the use of different software has become widespread. This progress allowed the researches above to employ such techniques in their vibration analyses. However, a simulation and analysis based on software are unable to match the actual working conditions of a roadheader [12]. Owing to a lack of actual data from actual working conditions, little research has applied actual data to a modal analysis of vibration. This paper aims to analyze the vibration of the rotary table of a roadheader to put forward an accurate vibration analysis method of the equipment used in an underground coalmine.

In the following sections, a vibration model of a rotary table built using Pro/E is described, along with the actual data from the coalmine that were collected, filtrated, and imported into the model. Based on an actual modal analysis and the above data, a simulated vibration model of a rotary table load was built. The vibration characteristics were then analyzed through a vibration simulation. Finally, the simulation results were compared with the modal experiment. The results of a comparison between the simulation and experiment indicate that the vibration characteristics of a rotary table are reliable and reasonable.

\section{Analysis of Force and Structure}

2.1. Introduction of Roadheader and Rotary Table. A rotary table is a structural component connecting the cutting arm and body of a roadheader [13, 14]. It has a significant influence on the reliability and stability of the complete machine. A general rotary table is composed of a revolved body, slewing bearing, and two symmetrical rotary cylinders, as shown in Figure 1 . In Figure 1(a), 1 is the cutting head, 2 is the cutting arm, 3 is the hoist cylinder, 4 is the rotary table, and 5 is angling cylinder. In Figure 1(b), 1 is the rotary body, 2 is the rotating support, and 3 is the angling cylinder.

The cylinders provide a drive force to revolve the rotary table, thereby allowing the cutting arm to revolve when excavating a roadway. The rotary table and body are connected

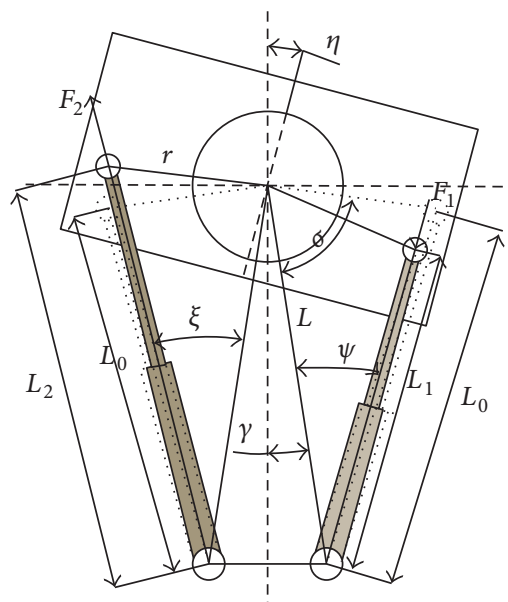

Figure 2: Force diagram of a rotary table.

using a pivotal bearing. The rotary table is fixed to the pivotal bearing by bolts that are closely distributed around the table center. At the same time, the pivotal bearing is also fixed to the roadheader body using bolts.

2.2. Force Analysis. The force of a rotary table along the horizontal plane is shown in Figure 2. Here, $\eta$ is the rotational angle of the rotary table, and $F_{1}$ is the force of the first cylinder. The direction of $F_{1}$ is the same as that of the two hinge joints of the first cylinder, as is that of $F_{2}$. In addition, $L$ is the distance between the rotation center and the hinge joint of the cylinder, $L_{1}$ and $L_{2}$ are the lengths of these two cylinders when $\eta$ is not zero, and $F_{z}$ is the force produced by the vibration. Under the action of $F_{z}, \delta$ is the dip angle of the cutting arm. Thus, the moment of the center of gyration can be described as

$$
M_{1}=F_{z} *(c * \cos \delta+d) .
$$

In (1), $d$ is the horizontal distance between the rotation center and hinge joint of the cutting arm. Based on the law of cosines, (2) can be written as

$$
\begin{aligned}
& L_{1}=\sqrt{r^{2}+L^{2}-2 * r * L * \cos (\delta-\eta)}, \\
& L_{2}=\sqrt{r^{2}+L^{2}-2 * r * L * \cos (\delta+\eta)} .
\end{aligned}
$$

When the rotary table rotates around $\eta$, the law of sines can be employed in the triangle connecting the two hinge 
joints and the rotary table center. In addition, $\Psi$ and $\xi$ are the angles between one of the cylinders and the line connected by the center and one of the hinge joints, as shown in Figure 2.

Thus, (3) can be written as

$$
\begin{gathered}
\psi=\arcsin \frac{r \sin (\delta-\eta)}{L_{1}}, \\
\xi=\arcsin \frac{r \sin (\delta+\eta)}{L_{2}} .
\end{gathered}
$$

If the rotary table rotates uniformly around the center of the gyration, the direction of the contact force between the rotary table and the frame points toward the center of gyration. The moment provided by the contact force is 0 . According to moment balance, the moment provided by the cylinder is equal to the moment of $F_{z}$. Thus, the moment of the angled cylinder is shown through

$$
M_{1}=F_{1} r \sin (\psi+\delta-\eta)+F_{2} r \sin (\psi+\delta+\eta)_{1} .
$$

The force provided by the cylinder can be calculated based on the product of the cylinder pressure and the effective piston area. The braced force of the cylinder is in direct proportion to the effective piston area. In addition, $S_{1}$ is the effective area of the cylinder, which can be calculated through the piston area minus the piston rod area, and $S_{2}$ is the piston area. Thus, (5) can be obtained as follows:

$$
\frac{F_{1}}{F_{2}}=\frac{P * S_{1}}{P * S_{2}}=\frac{S_{1}}{S_{2}}=C(<1, \text { constant }) .
$$

Based on (4) and (5), (6) can be obtained as

$$
\begin{aligned}
& \frac{F_{1}}{M_{1}}=\frac{C}{r[C \sin (\psi+\delta-\eta)+\sin (\varepsilon+\delta+\eta)]}, \\
& \frac{F_{2}}{M_{1}}=\frac{1}{r[C \sin (\psi+\delta-\eta)+\sin (\varepsilon+\delta+\eta)]} .
\end{aligned}
$$

According to (6), when the rotating angle is certain, $F_{1}$ is in direct proportion to $M_{1}$, and when $F_{z}$ is constant, $\delta$ is zero, and $M_{1}$ reaches the maximum level.

\section{Model of Vibration}

3.1. Three-Dimensional (3D) Solid Model. During the cutting of the roadheader, the swing of the cutting arm is driven by the rotation of the rotary table [15]. The resistance and impulse load caused by cutting the coal may be transmitted from the cutting head and arm. To simplify the calculation, some unimportant parts are dismissed, and a solid model of the rotary table, as shown in Figure 3, could be developed.

3.2. Selection and Import of the Vibration Data. To record the data of the roadheader vibration, the state parameters and position angle of the roadheader working in the excavation face of an underground coalmine are recorded [16, 17]. Taking the work period of the roadheader as an example, the time series of the cutting head and load can be calculated, as shown in Figure 4.

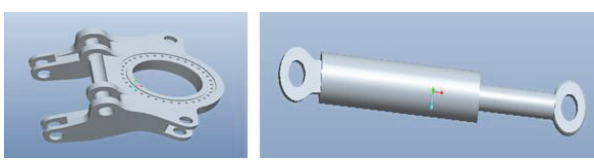

FIGURE 3: Solid model of the rotary table and cylinder.

TABLE 1: Simulation parameters.

\begin{tabular}{lc}
\hline Parameter type & Value \\
\hline Material & ZG35CrMo \\
Elasticity modulus & $210 \mathrm{GPa}$ \\
Density & $7800 \mathrm{~kg} / \mathrm{m}^{3}$ \\
Poisson's ratio & 0.3 \\
\hline
\end{tabular}

The monitoring period is $1,000 \mathrm{~s}$. According to the relationship between the time and torque, the load amplitude increases distinctly during this time period. In addition, during this time period, the force amplitude in the $z$-axis and $y$-axis also increases, and the impulse load and vibration of the roadheader are the most severe. At this time, a breakdown of the rotary table and other vulnerable parts can easily occur. Therefore, the simulated load data should be selected from this time period.

Because the sampling frequency is $1 \mathrm{~Hz}$ during the cylinder pressure measurement, the time series of the cutting head is unable to be applied during the simulation. Therefore, the data are selected and fitted by linear least square method for use in the vibration simulation.

After the load is imported, the force of the joints hinged to the rotary table, the cutting arm, and the cylinder are measured using ANSYS. The load on the rotary table under the working conditions can then be obtained. Based on an analysis of the rotary table, when $\eta$ is $20^{\circ}, \delta$ is $-15^{\circ}$, the pressure of the hoist and rotating cylinders is larger, and the force condition is complex. The force and torque are larger than at any other position angle, and this is therefore a typical case for the vibration analysis of a rotary table.

Taking the two hinge joints of the rotating cylinder and the table as examples, the force changes over time, as shown in Figure 5.

The force of all six marked points is processed using FFT, and the power spectrum density (PSD) and phase curves could be obtained for import into the vibration model of ADAMS. This could be regarded as the excitation load of the rotary table vibration model.

3.3. Vibration Model. The parameters of the roadheader simulated in ANSYS are shown in Table 1. In the finite element model of the rotary table, the RBE2 rigid constraint units are used. The degree of freedom (DOF) of the underside node and pins of the rotary table is constrained. The finite element model after the constraint is then analyzed, and the exported modal neutral file is imported into ADAMS [18]. Based on the MNF document and flexible body port, the vibration model is built using ADAMS, and the finite element and vibration models are developed, as shown in Figure 6. 


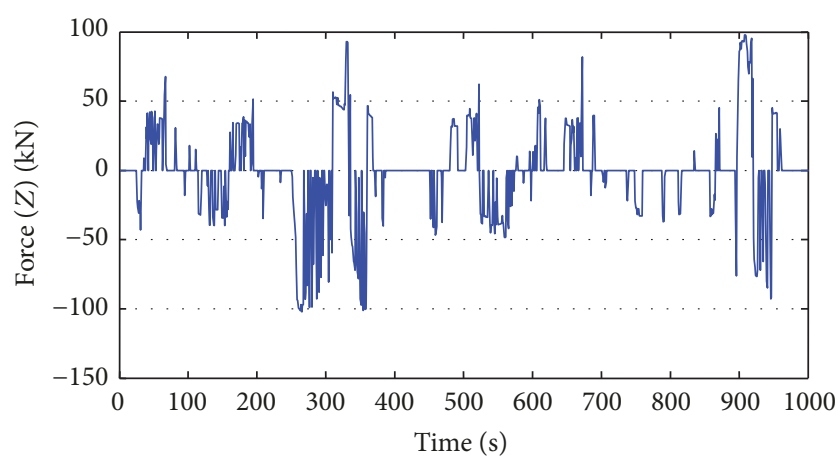

(a) The force in $Z$ direction changes over time

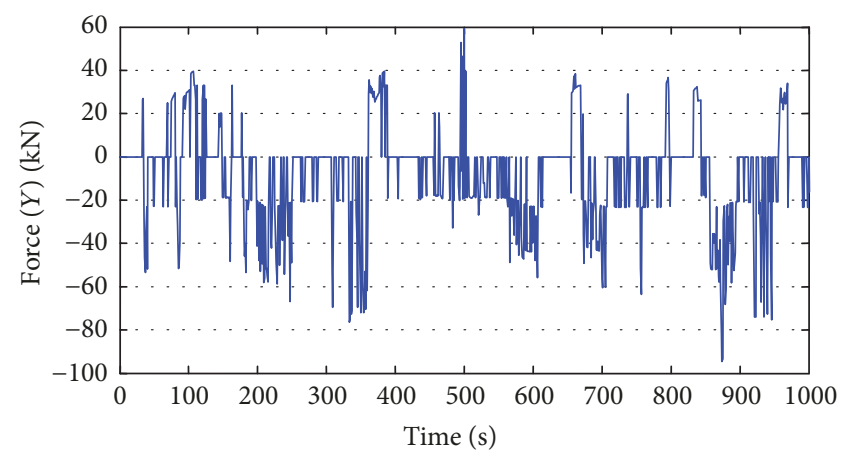

(b) The force in $Y$ direction changes over time

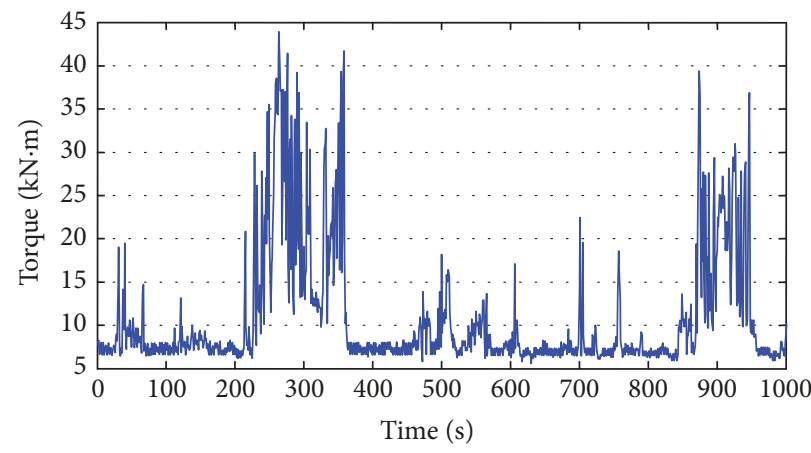

(c) The torque of the cutting head changes over time

FIGURE 4: Changes in torque and force of the cutting head over time.

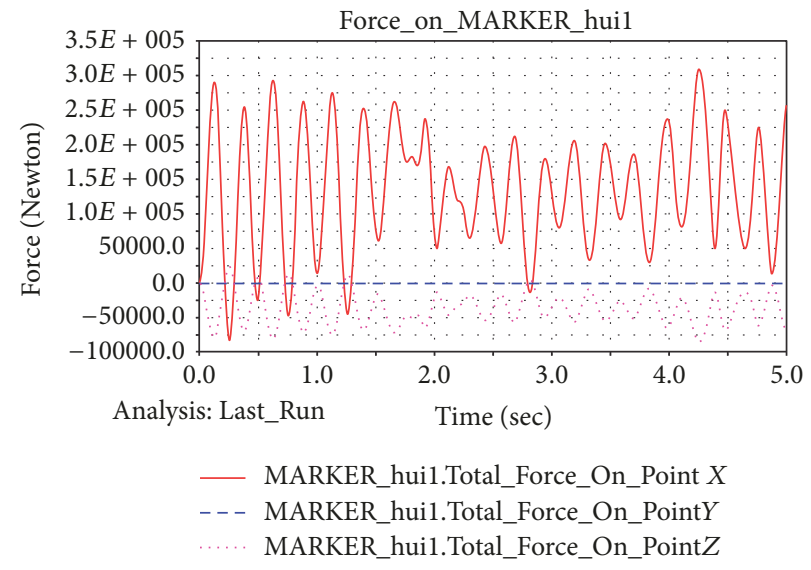

(a) The force of the 1st hinge point

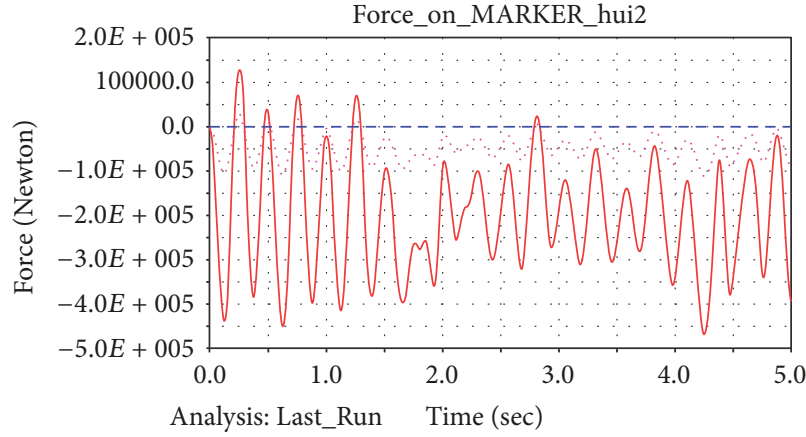

— MARKER_hui2.Total_Force_On_Point $X$

- - - MARKER_hui2.Total_Force_On_Point $Y$ MARKER_hui2.Total_Force_On_Point $Z$

(b) The force of the 2 nd hinge point

FIGURE 5: Changes in the force of the hinge joint over time.

In the vibration model, the rotary table rotates around the center at a $20^{\circ}$ angle. The rotating center and frame are linked using fixed joints, and the 6 DOFs of the center are constrained. The excitation points of the three different force directions are settled at the hinge joints between the cylinder and cutting motor. The monitoring points are marked near the hinge joints and vulnerable points. All of the vibration excitation is imported into the input channel for a vibration analysis. The frequency range of the excitation is 0 to $100 \mathrm{~Hz}$, with load steps of 500 .
In the finite element model of the rotary table, displacement of the nodes is not constrained. After the modal analysis, the modal frequency and corresponding vibration mode could be obtained. The first six-order frequency and vibration modes under free conditions are shown in Figure 7 . Figures $7(\mathrm{a})-7(\mathrm{f})$ are the first 6 orders' vibration mode simulation pictures. The detailed description of the transformation and frequency is provided in Table 2. It introduces the detailed vibration amplitude, location, and inherent frequency of the first 6 orders. 


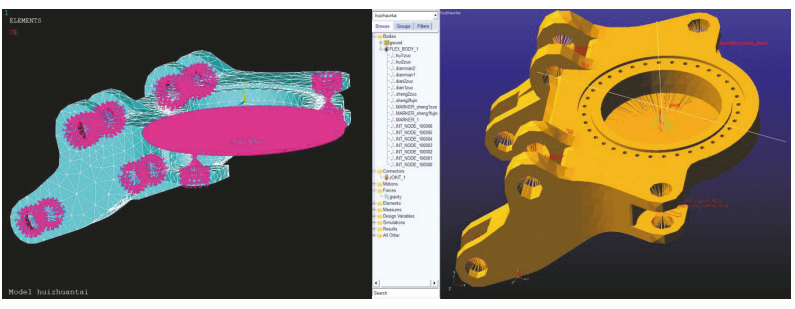

FIGURE 6: Finite element and vibration models of the rotary table.

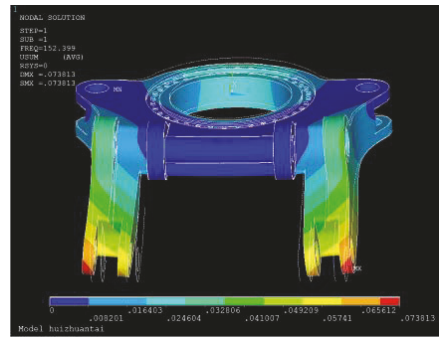

(a) First order of vibration

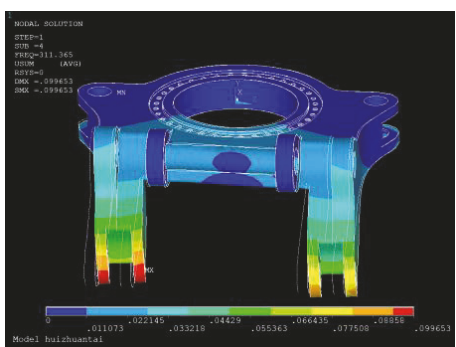

(d) Fourth order of vibration

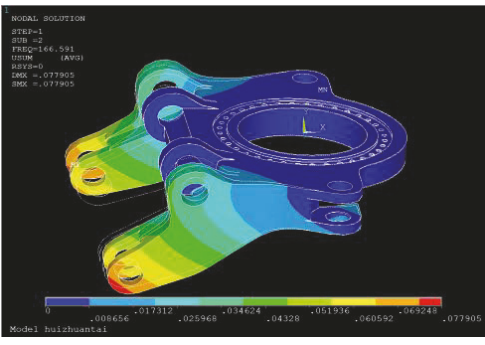

(b) Second order of vibration

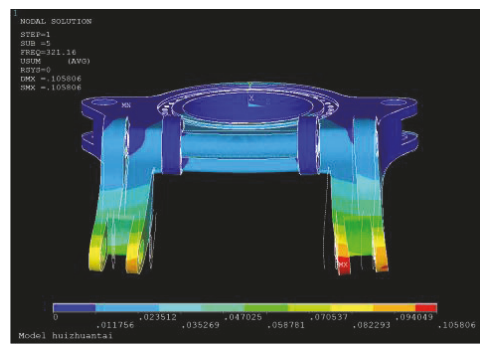

(e) Fifth order of vibration

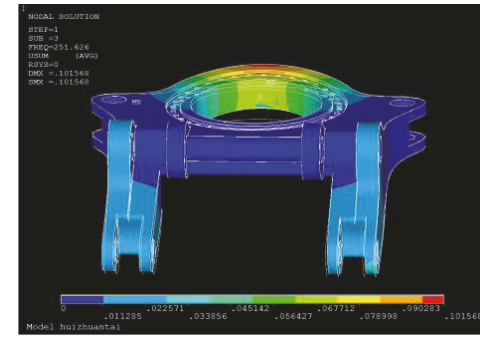

(c) Third order of vibration

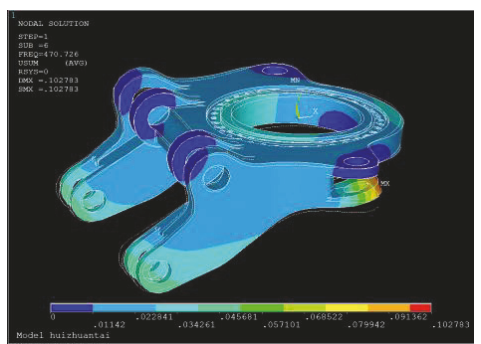

(f) Sixth order of vibration

FIGURE 7: First six modal vibration modes of the rotary table.

TABLE 2: First six modal modes of the rotary table.

\begin{tabular}{|c|c|c|c|c|c|c|c|}
\hline \multirow{3}{*}{ Order } & \multirow{3}{*}{$\begin{array}{c}\text { Inherent } \\
\text { frequency }(\mathrm{Hz})\end{array}$} & \multicolumn{6}{|c|}{ Mode of vibration } \\
\hline & & \multicolumn{2}{|c|}{ Arm } & \multicolumn{2}{|c|}{ Shoulder } & \multicolumn{2}{|c|}{ Posterior } \\
\hline & & Direction & Amplitude & Direction & Amplitude & Direction & Amplitude \\
\hline (1) & 152.399 & $\begin{array}{c}\text { Outward and } \\
\text { upward }\end{array}$ & Large & None & Little & Downward & Small \\
\hline$(2)$ & 166.591 & $\begin{array}{l}\text { Left (entirety) } \\
\text { Upward (left } \\
\text { arm) } \\
\text { Downward } \\
\text { (right arm) }\end{array}$ & Medium & $\begin{array}{c}\text { Upward (left) } \\
\text { Downward } \\
\text { (right) }\end{array}$ & Small & Little & None \\
\hline (3) & 251.626 & $\begin{array}{c}\text { Outward and } \\
\text { upward }\end{array}$ & Small & Downward & Small & Upward & Large \\
\hline$(4)$ & 311.365 & $\begin{array}{c}\text { Right (entirety) } \\
\text { Upward (left } \\
\text { arm) } \\
\text { Downward } \\
\text { (right arm) }\end{array}$ & Largest in right & $\begin{array}{c}\text { Downward } \\
\text { (center section) }\end{array}$ & Small & Little & Little \\
\hline (5) & 321.16 & $\begin{array}{l}\text { Outward and } \\
\text { downward }\end{array}$ & $\begin{array}{l}\text { Right arm is } \\
\text { larger than the } \\
\text { left }\end{array}$ & $\begin{array}{l}\text { Downward } \\
\text { (center) }\end{array}$ & Small & Downward & Small \\
\hline$(6)$ & 470.726 & $\begin{array}{c}\text { Outward and } \\
\text { downward }\end{array}$ & Small & Upward (center) & Small & Downward & Larger \\
\hline
\end{tabular}




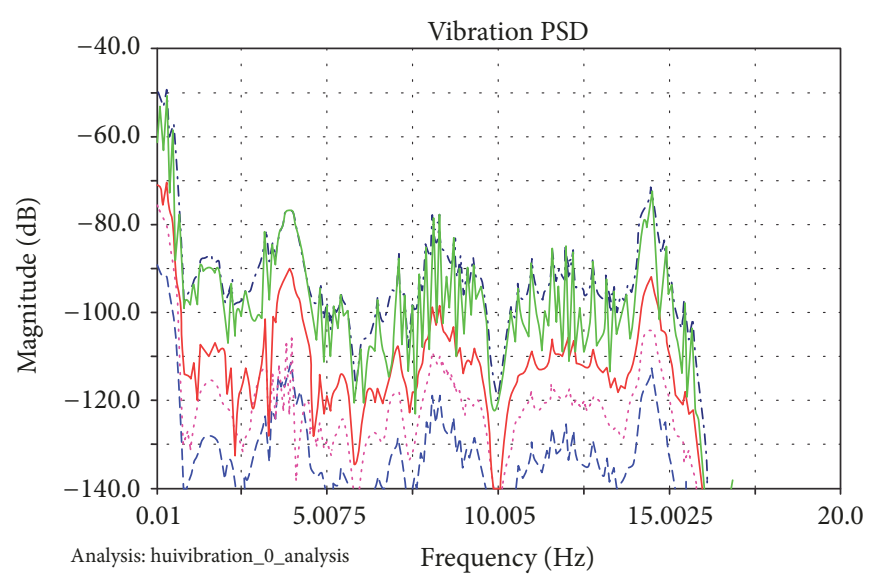

_- huiVibration_0: Output_dian1zuo PSD
--- huiVibration_0: Output_dimian1 PSD
… huiVibration_0: Output_huilzuo PSD
-.- huiVibration_0: Output_sheng1fujin PSD
- huiVibration_0: Output_sheng1zuo PSD

(a) The PSD of the left gauge point

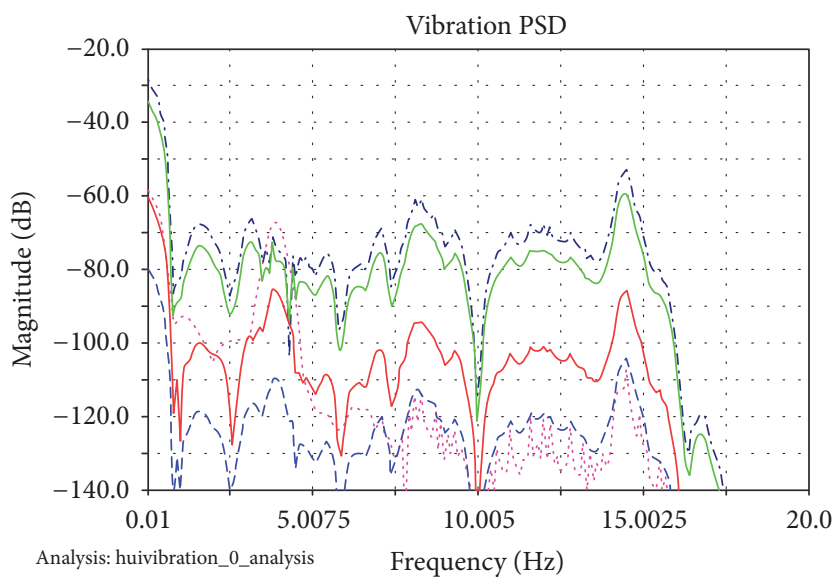

— huiVibration_0: Output_dian2zuo PSD

- - - huiVibration_0: Output_dimian2 PSD huiVibration_0: Output_huizzuo PSD

...- huiVibration_0: Output_sheng2fujin PSD

— huiVibration_0: Output_sheng2zuo PSD

(b) The PSD of the right gauge point

FIGURE 8: PSD of the gauge point.

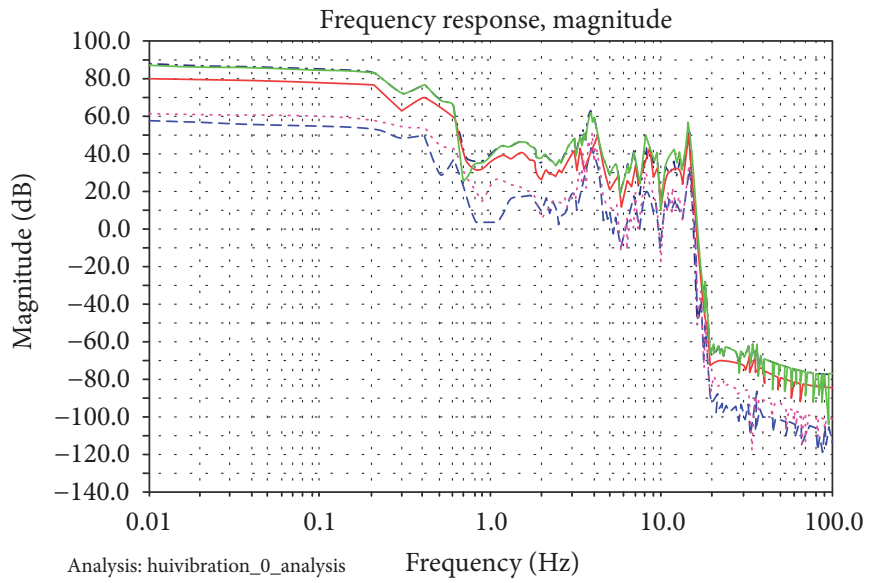

__ huiVibration_0: Sum of All Inputs Output_dian1zuo Response

--- huiVibration_0: Sum of All Inputs Output_dimian1 Response

..... huiVibration_0: Sum of All Inputs Output_huilzuo Response

. ..- huiVibration_0: Sum of All Inputs Output_shenglfujin Response

_ huiVibration_0: Sum of All Inputs Output_sheng1zuo Response

(a) The frequency of the left gauge point

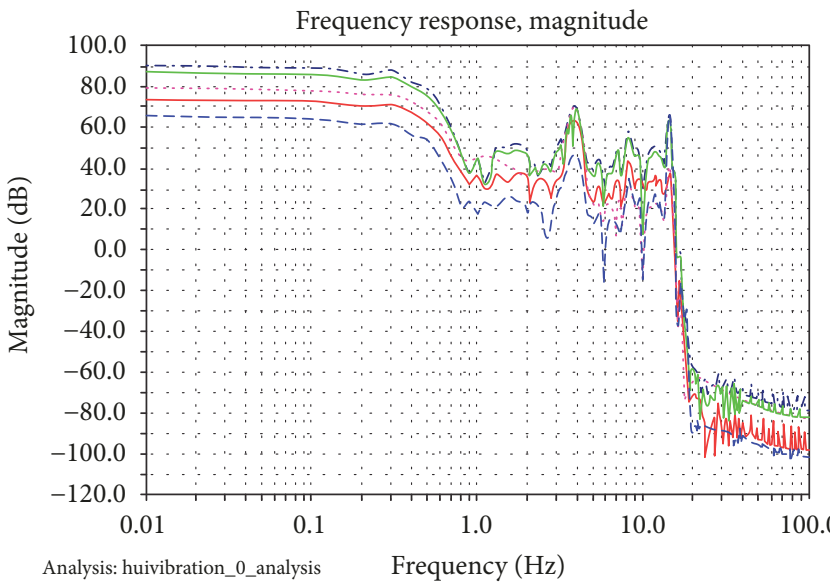

_ huiVibration_0: Sum of All Inputs Output_dian2zuo Response

--_ huiVibration_0: Sum of All Inputs Output_dimian2 Response

...... huiVibration_0: Sum of All Inputs Output_hui2zuo Response

...- huiVibration_0: Sum of All Inputs Output_sheng2fujin Response

__ huiVibration_0: Sum of All Inputs Output_sheng2zuo Response

(b) The frequency of the right gauge point

FIGURE 9: Frequency response amplitude curve of the gauge point at the rotary point.

3.4. Analysis of the Vibration. In the vibration of a rotary system, an excitation force occurs on every hinge joint in 3 directions. Every exciting force corresponds to an input channel, and the response from every output channel varies. In a linear system, the response of every channel is a summation of every force response in the corresponding channel. The PSD of the output channel is shown in Figure 8.

According to Figure 8, the PSD reaches its maximum level when the frequency is $1.5,3.9,7.1,8.3$, or $14.5 \mathrm{~Hz}$. The vibration response of the rotary table contains a greater amount of vibration energy when the frequency nears these points. At the same frequency, the vibration amplitude is also larger. The reaction of the vibration performance in the frequency domain could be reflected based on the frequency response, as can the relation between the input and output.

Because a rotary table is symmetric, the frequency response of the sum of excitations of the symmetrical points is similar. The amplitude curves of the symmetrical point frequency response are shown in Figure 9. 
TABLE 3: Equipment used in the test.

\begin{tabular}{|c|c|c|c|}
\hline Number & Name & Type & Parameters and number \\
\hline (1) & $\begin{array}{l}\text { DASP analysis } \\
\text { platform }\end{array}$ & DASP-V10 & 1 \\
\hline$(2)$ & Modal software & $\begin{array}{l}\text { MIMO modal } \\
\text { analysis software }\end{array}$ & 1 \\
\hline (3) & $\begin{array}{c}\text { Signal collecting } \\
\text { device }\end{array}$ & INV3018C & 8 channels/24 bits; sample frequency: $25.6 \mathrm{kHz}$ \\
\hline$(4)$ & Acceleration sensor & INV9824 & $\begin{array}{c}1 \sim 15 \mathrm{kHz}, 5 \mathrm{mV} / \mathrm{g} \text {, range: } 1000 \mathrm{~g} \text {, DPI: } 0.04 \mathrm{~m} / \mathrm{s}^{2} ; \text { Imp: } 2 \sim 10 \mathrm{~mA} \text {; } \\
\text { impedance }<100 \Omega \text {, voltage } 1-28 \mathrm{DCV} \text {, operating temperature: } \\
-20 \sim 120^{\circ} \mathrm{C}\end{array}$ \\
\hline$(5)$ & Nylon hammer & DFC-2 & $12.5 \mathrm{t}$ force sensor inside 1 \\
\hline$(6)$ & Conditioner & INV1841C & 1 \\
\hline \multirow{5}{*}{ (7) } & \multirow{5}{*}{ Others } & Computer & 1 \\
\hline & & Magnetic suction & 10 \\
\hline & & Chalk & 10 \\
\hline & & Insulating tape & 3 \\
\hline & & Wire & 20 \\
\hline
\end{tabular}

When all of the channels are excited, the amplitude of the frequency response function increases from 0 to $20 \mathrm{~Hz}$. When the frequency is greater than $20 \mathrm{~Hz}$, there is a sharp decrease in this large amplitude. A minor response of the rotary table also occurs when the excitation frequency is greater than $20 \mathrm{~Hz}$. When the frequency is similar, the amplitude of the points near the two arms and cylinder hinge joints is larger, and that of the undersurface of the rotary table is minimal. The largest vibration parts of the rotary table are the most vulnerable parts. When the frequency is 4 or $14.6 \mathrm{~Hz}$, the response amplitude is larger than that at a frequency of $10 \mathrm{~Hz}$.

\section{Vibration Modal Tests}

To verify the accuracy of the analysis method, vibration modal test of a EBZ-160 roadheader rotary table was conducted [19]. The experiment system used in the modal tests consisted of an excitation system, a measurement system, and an analysis system, as shown in Figure 10.

In this modal experiment, the excited system included an exciting hammer and force sensor. The force sensor was installed inside the hammer, and thus the input exciting signal could be measured directly when the hammer knocked the rotary table. An acceleration sensor was installed at the measurement point of the rotary table, and the response at every point could be measured. Both the exciting signal and the response could be recorded concurrently using a signalcollection device.

Because a vibration analysis using software is under free conditions, the modal parameters of the rotary table during these tests should also be under such condition [20]. To imitate the free condition of the rotary table, it was hung up using a crown block. For safety reasons, the upholder was laid on the ground. During the test, the hammer method was employed for the excitation. Because of the relatively lower weight of the rotary table, any additional weight

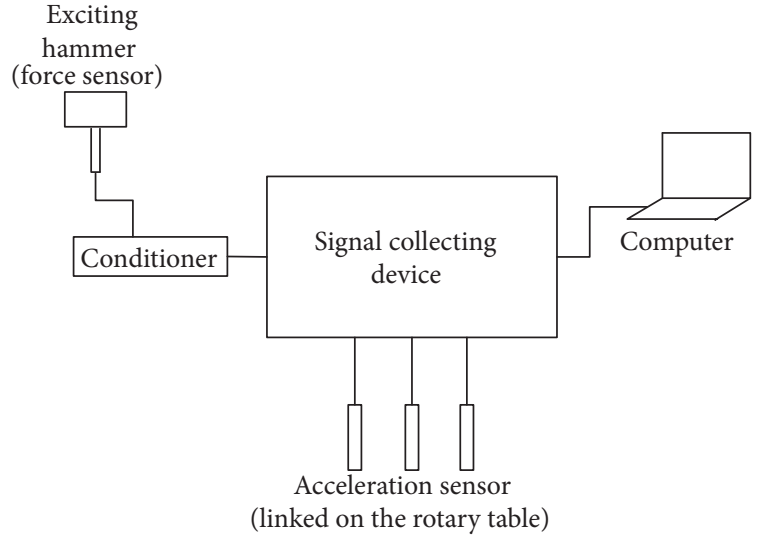

Figure 10: System diagram of the modal experiment.

would be influential. Therefore, the hammering method was applied for this test. Moreover, the method is convenient for experimentation.

The selection of the hammer is a fundamental aspect of this method. Because the stiffness of the rotary table is large and only low-frequency vibration and low modality need to be analyzed, a nylon hammer was chosen for this experiment. Thus, the type and parameters of all the instruments in this experiment are as shown in Table 3.

During this experiment, as many response and excitations points as possible were applied, and the measurement points were evenly arranged. More measurement points were arranged in the vulnerable area, as determined based on the breakdown statistics available, so as to reduce any modal leaks. The marks on the rotary table and measurement points on the DASP are shown in Figure 11.

There were four excitation points on the rotary table. One point was in the horizontal direction ( $X$-axis) at point 46. Another was in the axial direction ( $Y$-axis) at point 1 . The remaining two points were in the vertical direction at points 

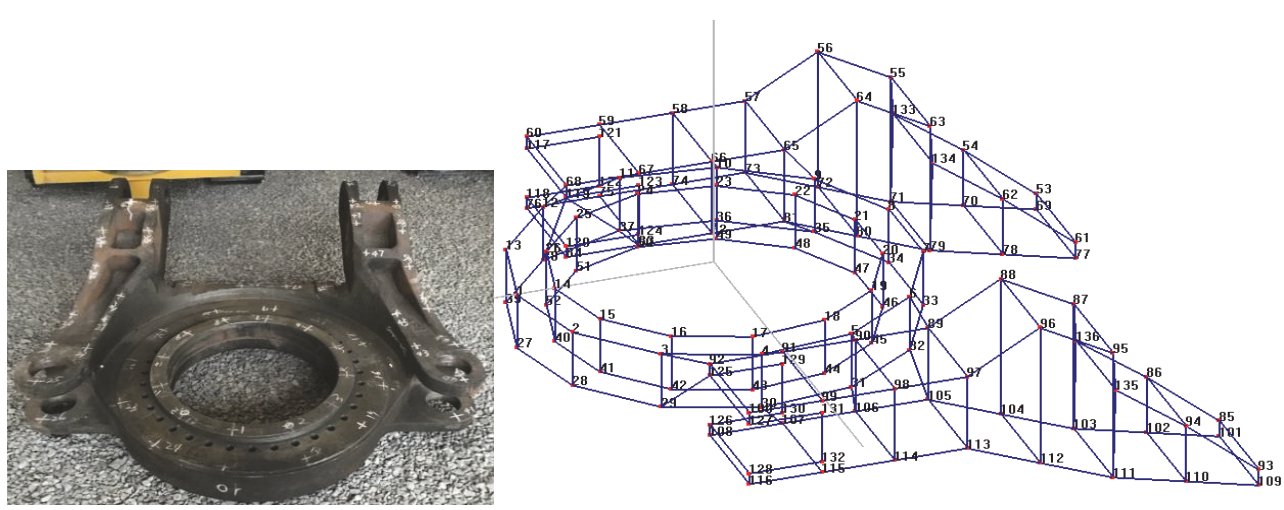

FIGURE 11: Measurement points marked on the rotary table.

TABLE 4: Modal experiment results of the rotary table.

\begin{tabular}{|c|c|c|c|c|c|c|c|}
\hline \multirow{3}{*}{ Order } & \multirow{3}{*}{$\begin{array}{c}\text { Inherent } \\
\text { frequency }(\mathrm{Hz})\end{array}$} & \multicolumn{6}{|c|}{ Mode of vibration } \\
\hline & & \multicolumn{2}{|c|}{ Arm } & \multicolumn{2}{|c|}{ Shoulder } & \multicolumn{2}{|c|}{ Posterior } \\
\hline & & Direction & Amplitude & Direction & Direction & Amplitude & Direction \\
\hline (1) & 139.581 & $\begin{array}{l}\text { Lower right side } \\
\text { and left upper } \\
\text { side }\end{array}$ & Larger & None & Little & Downward & Small \\
\hline$(2)$ & 170.601 & $\begin{array}{l}\text { Left (entirety) } \\
\text { Upward (left } \\
\text { arm) } \\
\text { Downward } \\
\text { (right arm) }\end{array}$ & Normal & $\begin{array}{l}\text { Upward (left) } \\
\text { Downward } \\
\text { (right) }\end{array}$ & Small & Little & None \\
\hline (3) & 270.549 & $\begin{array}{c}\text { Outward and } \\
\text { upward }\end{array}$ & Small & Downward & Small & Upward & Large \\
\hline$(4)$ & 363.650 & $\begin{array}{l}\text { Right (entirety) } \\
\text { Upward (left } \\
\text { arm) } \\
\text { Downward } \\
\text { (right arm) }\end{array}$ & $\begin{array}{l}\text { Right arm is } \\
\text { larger than the } \\
\text { downward }\end{array}$ & $\begin{array}{c}\text { Downward } \\
\text { (center section) }\end{array}$ & Small & Little & Little \\
\hline (5) & 414.087 & $\begin{array}{c}\text { outward and } \\
\text { downward }\end{array}$ & $\begin{array}{l}\text { right arm is } \\
\text { larger than the } \\
\text { left }\end{array}$ & $\begin{array}{l}\text { downward } \\
\text { (center) }\end{array}$ & small & downward & small \\
\hline (6) & 438.216 & $\begin{array}{c}\text { outward and } \\
\text { downward }\end{array}$ & small & upward (center) & small & downward & larger \\
\hline
\end{tabular}

14 and 26. During the experiment, the excitation points were knocked. Meanwhile, the acceleration sensors were moved in batches, and, in this way, 62 points could be covered. The coefficient of association of the target frequency range should be close to 1 . When the coefficient did not satisfy this requirement, the step was repeated until a satisfying result was obtained.

For a quality hammer excitation, the hammer needed to be perpendicular to the plane of the excitation point, knocking the point quickly and being quickly brought back. In addition, the excitation force needed to be averaged over three attempts to avoid random errors as much as possible. All of the data were then recorded. The data were processed using DASP and then fitted through PolyIIR. The vibration order was determined based on a stabilization diagram. Finally, the vibration mode of the modal, the frequency, and the damping ratio were obtained.

\section{Results and Discussion}

A description of the transformation and frequency is provided in Table 4, and a comparison between the experiment and simulation is shown in Table 5.

The vibration mode, frequency, and damping ratio determined through the experiment results correspond to the simulation results. However, there is a clear distinction in the vibration mode between the simulation and experiment. The simulation was unable to recognize the lower right and left upper side vibrations of the rotary table. Although both the simulation and experiment made use of free conditions, 
TABLE 5: Comparison between the experiment and simulation.

\begin{tabular}{lcccc}
\hline \multirow{2}{*}{ Order } & \multicolumn{2}{c}{ Frequency $(\mathrm{Hz})$} & \multicolumn{2}{c}{ Damping ratio } \\
& Simulation & Experiment & Simulation & Experiment \\
\hline$(1)$ & 152.399 & 139.581 & 0.999 & 1.469 \\
$(2)$ & 166.591 & 170.601 & 0.645 & 0.400 \\
$(3)$ & 251.626 & 270.549 & 0.274 & 0.155 \\
$(4)$ & 311.365 & 363.650 & 0.199 & 0.204 \\
$(5)$ & 321.16 & 414.087 & 0.247 & 0.258 \\
$(6)$ & 470.726 & 438.216 & 0.086 & 0.092 \\
\hline
\end{tabular}

a difference in the assembly and constraint remained. The simulation was based on the actual assembly conditions, and hinge pins were used. Therefore, the vibration of the hinge pins in the adjacent area was restricted to a certain extent, and thus this type of vibration cannot be recognized through a simulation. As a result, despite some subtle distinctions, the consistency between the simulation and experiment is clear, and thus this type of analysis approach can be deemed reasonable and feasible for this particular equipment.

\section{Conclusions}

According to the simulation results for the first six vibration modes, as well as the frequency, damping ratio, and the corresponding experiment results, the vibration of a rotary table in a roadheader used in an underground coalmine was determined. A vibration model of the rotary table was created, which includes the data collected from the underground coalmine. A simulation of the vibration was then conducted using ADAMS, leading to solved terms regarding the vibration mode, frequency, and damping ratio.

(1) This study introduced a vibration model and test data imported into an analysis of the rotary table vibration, the results of which were shown to correspond with the modal experiments. The dominant frequency of the rotary table vibration response is determined by this method.

(2) Based on the above analysis, it could be concluded that the amplitude of the points near the two arms and cylinder hinge joints are the largest area of the rotary table. The vibration of the rotary table undersurface is the minimum. Compared with the common breakdown of the rotary table, the breakdown area of the rotary table is corresponding to the largest vibration points determined in this study. Therefore, this type of vibration analysis is reasonable and feasible. In addition, the tested data from the underground coalmine is developed to a greater extent to be analyzed.

(3) The vibration energy during cutting could be transferred by the cutting head, cutting arm, and rotary table. According to the vibration analysis of the rotary table, the vibration elimination parts could be located. According to the vibration analysis, the vulnerable parts of the rotary table could be determined and predicted. During the design and manufacturing, these vulnerable parts could be reinforced or improved by structure optimization and vibration reduction measures.
(4) As a further step, when applying a vibration model and tested data to the rotary table vibration, other vibration components of a roadheader such as the cutting head and the cutting arm could also be analyzed through the proposed method, with very reliable precision. In addition, optimization of the components can be achieved based on the analysis presented herein. Based on this vibration analysis method of different components of a roadheader, the cutting efficiency, stability, and cost could be improved in some degree.

Some relative conclusions found through the analysis of the vibration can be summarized as follows:

(1) There are still some differences between the simulation and experiment results, and a modal experiment would be more reliable if it could be carried out under real working conditions.

(2) The vibration mode, frequency, and damping ratio of the rotary table of a roadheader applied in the experiment depend on the excitation time, intensity, knock angle, and other factors, so it is not accurate completely. For a better correspondence between the simulation and experiment results, the knocking approach will require several attempts.

\section{Nomenclature} ADAMS: Automatic Dynamic Analysis of
Mechanical Systems

Pro/E: Pro/Engineering

FFT: $\quad$ Fast Fourier Transformation

PSD: $\quad$ Power spectrum density

ANSYS: Software of finite element analysis

RBE2: The 2nd rigid binding element in ANSYS; the load is transmitted by the parasite displacement DOF

DOF: $\quad$ Degree of freedom

MNF: Modal neutral file

DASP: Data Acquisition and Signal Processing

PolyIIR: Infinite impulse response filtering model algorithm.

\section{Conflicts of Interest}

The authors declare that there are no conflicts of interest regarding the publication of this paper.

\section{Acknowledgments}

This work is supported by the National Basic Research Program of China (973 Project) (2014CB046306).

\section{References}

[1] O. Acaroglu and H. Ergin, "A new method to evaluate roadheader operational stability," Tunnelling and Underground Space Technology, vol. 21, no. 2, pp. 172-179, 2006.

[2] E. M. Eyyuboglu and N. Bolukbasi, "Effects of circumferential pick spacing on boom type roadheader cutting head performance," Tunnelling and Underground Space Technology, vol. 20, no. 5, pp. 418-425, 2005. 
[3] O. Acaroglu and H. Ergin, "The effect of cutting head shapes on roadheader stability," Transactions of the Institutions of Mining and Metallurgy, Section A: Mining Technology, vol. 114, no. 3, pp. A140-A146, 2005.

[4] O. Z. Hekimoglu and M. Ayhan, "Effects of cutting head motion on the boom length of rock and coal cutting machines," Mineral Resources Engineering, vol. 8, no. 4, pp. 381-389, 1999.

[5] J. Toraño Álvarez, M. Menéndez Álvarez, and R. Rodríguez Díez, "Experimental results of a low-power roadheader driving a gallery with different types of rock at the face," Tunnelling and Underground Space Technology, vol. 18, no. 4, pp. 395-404, 2003.

[6] P. A. A. Laura and R. E. Rossi, "Transverse vibrations of a thin, elastic plate of regular hexagonal shape [1]," Journal of Sound and Vibration, vol. 256, no. 2, pp. 367-372, 2002.

[7] D. Tan, Q. Wang, and Y. Wu, "Modal Analysis of In-Wheel Motor-Driven Electric Vehicle Based on Bond Graph Theory," Shock and Vibration, vol. 2017, Article ID 6459154, 9 pages, 2017.

[8] Y. Yang, Y. Qu, X. Tang, Y. Chu, and M. Wu, "Vibration Test and Analysis of a Working Tunnel Boring Machine (TBM) in Underground Mine," DEStech Transactions on Engineering and Technology Research, 2016.

[9] Z. Jianlong, "Research on vibration characteristics of heavy roadheader cutting unit," Tech. Rep., Liaoning Technical University, Fuxin, China, 2011.

[10] C. Labra, J. Rojek, E. Oñate, and F. Zarate, "Advances in discrete element modelling of underground excavations," Acta Geotechnica, vol. 3, no. 4, pp. 317-322, 2008.

[11] H. Ergin and O. Acaroglu, "The effect of machine design parameters on the stability of a roadheader," Tunnelling and Underground Space Technology, vol. 22, no. 1, pp. 80-89, 2007.

[12] I. J. Drygala and J. M. Dulinska, "A theoretical and experimental evaluation of the modal properties of a cable-stayed footbridge," in Proceedings of the 10th International Conference on Structural Dynamics, EURODYN 2017, pp. 2937-2942, Italy, September 2017.

[13] W. Harizi, S. Kaidi, A. Monnin, N. El Hajj, Z. Aboura, and M. Benzeggagh, "Study of the Dynamic Response of PolymerMatrix Composites Using an Innovative Hydraulic Crash Machine," Journal of Dynamic Behavior of Materials, vol. 1, no. 4, pp. 359-369, 2015.

[14] H. L. Guntur, W. Hendrowati, and T. Budiarto, "Modeling and analysis of hybrid shock absorber for military vehicle suspension," Applied Mechanics and Materials, vol. 493, pp. 315320, 2014.

[15] W. Jingsheng and W. Miao, China modern roadheader in coal mine, China Coal Industry Publishing House, Beijing, China, 2015.

[16] H. Xiao, Y. Shao, and C. K. Mechefske, "Transmission of vibration and energy through layered and jointed plates subjected to shock excitation," Proceedings of the Institution of Mechanical Engineers, Part C: Journal of Mechanical Engineering Science, vol. 226, no. 7, pp. 1765-1777, 2011.

[17] S. T. A. Gillani and N. Butt, "Excavation Technology for Hard Rock Problems and Prospects," Journal of Energy and applied Sciences, vol. 4, no. 1, pp. 24-33, 2009.

[18] J. Dzuba, M. Držík, G. Vanko et al., "Modal analysis of gallium nitride membrane for pressure sensing device," Key Engineering Materials, vol. 605, pp. 404-407, 2014.

[19] J. M. Ndambi, B. Peeters, J. Maeck et al., "Comparison of techniques for modal analysis of concrete structures," Engineering Structures, vol. 22, no. 9, pp. 1159-1166, 2000.
[20] D. Hanson, T. P. Waters, D. J. Thompson, R. B. Randall, and R. A. J. Ford, "The role of anti-resonance frequencies from operational modal analysis in finite element model updating," Mechanical Systems and Signal Processing, vol. 21, no. 1, pp. 7497, 2007. 


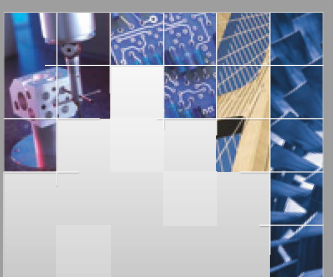

\section{Enfincering}
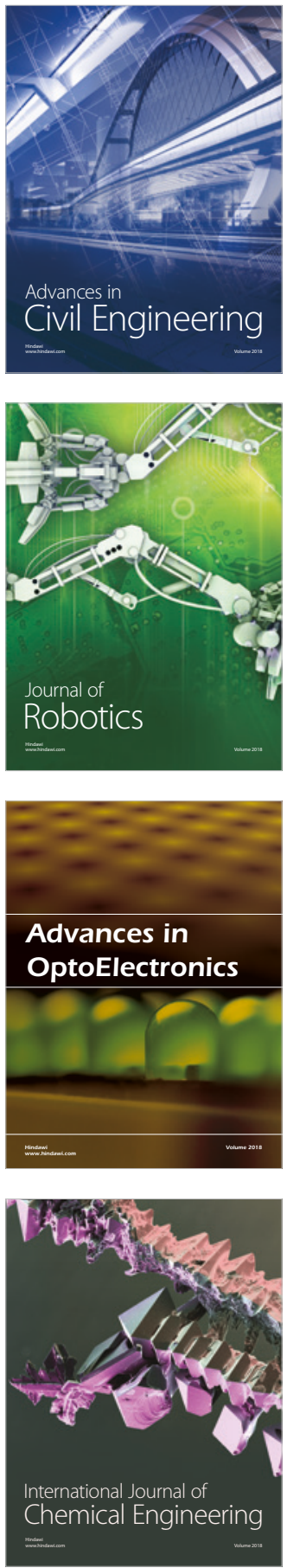

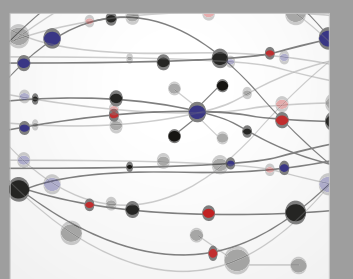

\section{Rotating \\ Machinery}

The Scientific World Journal

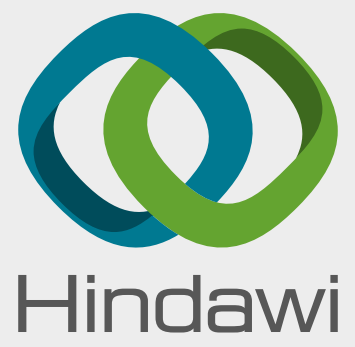

Submit your manuscripts at

www.hindawi.com
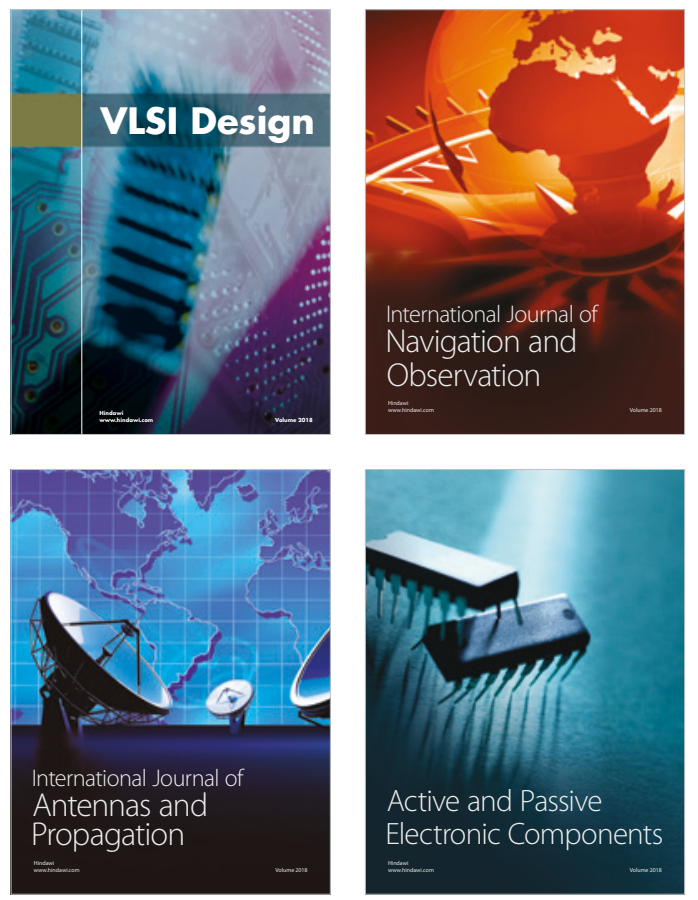
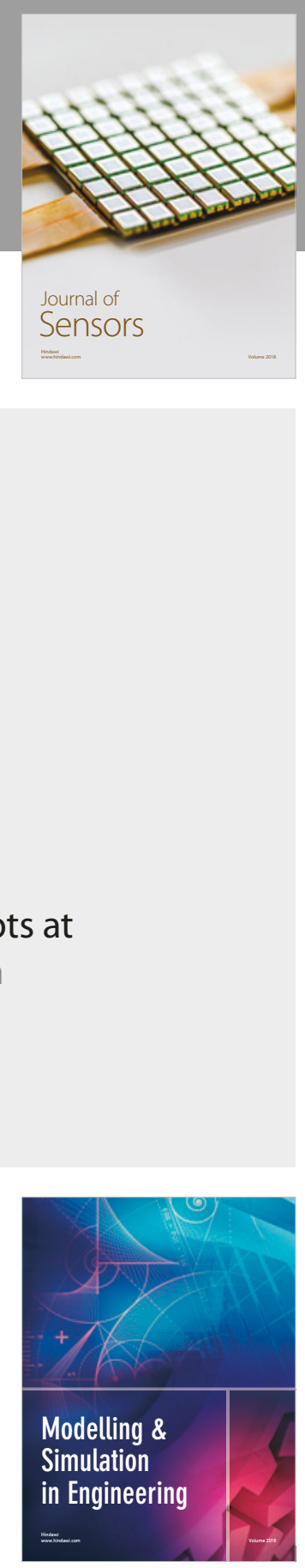

\section{Advances \\ Multimedia}
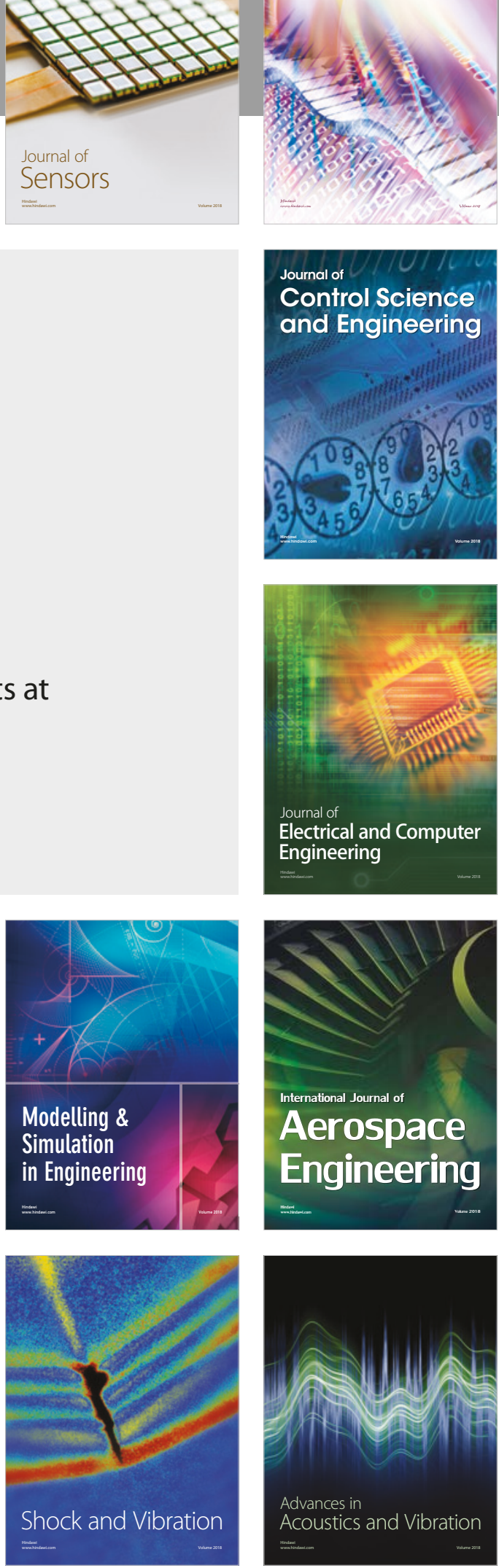